LA-UR $-88-443$

LA-UR $--88-443$

DE88 006467

\title{
TITLE A TRITIUM-COMPATIBLE PIEZOELECTRIC VAL.VE FOR THE TOKAMAK FUSION TEST REACTOR
}
AUTHOR(S): Don 0. Coffin, Steven P. Cole and Richard C. Wilhelm Tritium Science and Technology Group
Materials Science and Technology Division
Los Alamos National Laboratory
Los Alamos, New Hexico 87545
submitted to. Third Topical Meeting, Tritium Technology in Fission, Fusion and I sotr,pic Applications, May i-6, 1988, Toronto, Ontario, CANADA To be published in Fusion Technology.

\section{DISC I.AIMER}

\begin{abstract}
Thos remort was prepared as an account of work spmonsoled by an agency of the linted silutes

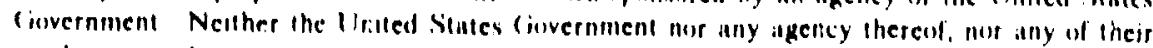

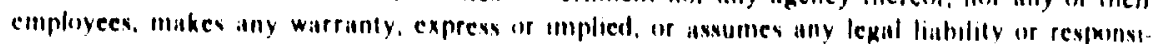

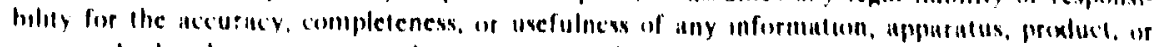

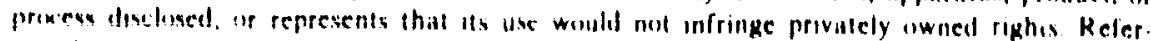

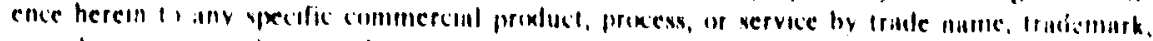

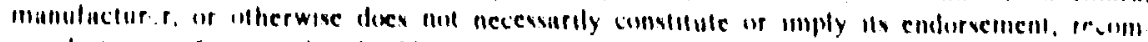



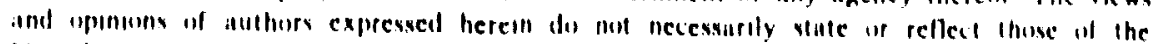

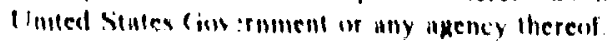

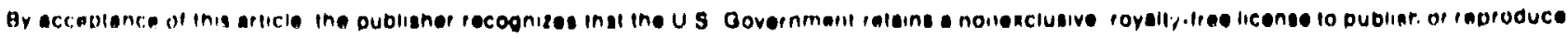

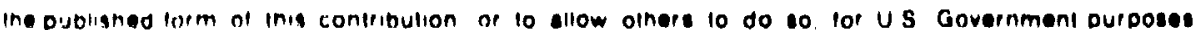




\title{
A TRITIUM-COMPATIBLE PIEZOELECTRIC VALVE FOR THE TOKAMAK FUSION TEST REACTOR
}

\author{
Don O. Coffin, Steven P. Cole, and Richard C. Wilhelm \\ Materials Science and Technology Division \\ Los Alamos National Latoratory, Los Alamos, New Mexico 87545
}

\section{INTRODUCTION}

In 1985 the Los Alamos National Laboratory undertook development and testing of a piezrelectric valve that would be suitable for a limited number of tritium gas injections at the Princeton Tokamak Fusion Test Reactor (TFTR). The technical objective was to develop a valve that could provide the full program of tritium gas injections planned for TFTR $(\sim 100)$ without leakage or degradation of performance dice to tritium. If leakage across the valve seat or other performance degradation should develop, it was desirable to make compensating adjustments without disassernbling the valve.

This work describes modifications made to a commercial piezoelectric valve to make it sifficiently tritium compatible for the TFTR tritium injection scenario. The results of testing the value for leakage and performance following a series of progressively more severe tritium exposures are also presented. Finally, a proposal for a totally radiation-compatibie piezoelectric valve, suitable for tritiun-burning fusion machines of the future, is described.

\section{THE PRINCETON HYDRUGEN PIEZO VALVE}

A commercial piezoelectric valve* has been used for hydrogen gas injections at both the Princeton 1 arge Torus (PLI) and at the TFTR with excellent results. An elegant computer control system, capable of real-time flow rate adjustments in response to plasma parameters, was developed 'for the valve. Thus, though the piezoelectric hydrogen injection valve contains many materials that are not iritium compatible, it is highly desirable to develop a valve which can be operated from the existing coittrol system. Moreover piezoelectric actuation is the only means known for making predictable, high-speer responses io real-time control in the large, varying magnetic fields surrounding a tokamak. For the TFTR application tritium compatibility is adequate if the outer case is impervious to trittum, and if performance is not degraded significantly during the anticinated schedule of 125 gas injections ${ }^{2}$ as specified in Table I.

\footnotetext{
-Precision I.cak Valve PV-10, Veeco Instruments Inc., Terminal Drive, Plainview, NY
} 11803. 
TABLE I

\section{TFIR TRITIUM INJECTIONS BY PIEZO VALVE}

(Total Pressure Constant at 1500 Torr)

\begin{tabular}{|c|c|c|c|c|}
\hline \multirow{2}{*}{$\begin{array}{l}\text { No. of } \\
\text { Shots in } \\
\text { Series }\end{array}$} & \multicolumn{2}{|c|}{ TRITIUM } & \multicolumn{2}{|c|}{ TRITIUM EXPOSURE } \\
\hline & $\%$ & $\begin{array}{l}\text { Press. } \\
\text { (atm) }\end{array}$ & $\begin{array}{l}\text { Per Shot } \\
\text { (atm-hr) }\end{array}$ & $\begin{array}{l}\text { Total } \\
\text { (atm-hr) }\end{array}$ \\
\hline 25 & 0.1 & 0.002 & 0.0002 & 0.005 \\
\hline 25 & 1.0 & 0.02 & 0.002 & 0.050 \\
\hline 25 & 2.5 & 0.05 & 0.005 & $0.1 \% 5$ \\
\hline 25 & 10.0 & 0.20 & 0.02 & 0.500 \\
\hline 25 & 100.0 & 2.00 & 0.20 & 5.000 \\
\hline
\end{tabular}

TOTALS

There are three areas of concern when using piezoelectric valves to inject tritium gas mixtures: (1) The presence of an ionizing gas in the space jetween surfaces separated bv high d.c. voltages might cause current leakage or veltage breakdown, with unpredictaole effects on valve performance; (2) the radiolysis of organic materials by tritium yields gaseous by-products that might introduce unacceptable levels of high- $Z$ impurities into the plasma; (3) to the extent that proper valve operation depends upon the properties of an elastomer, the perlormance will deteriorate as the elastomer is degraded by tritium exposure.

The problem of electrical breakdown in the presence of tritium was investigated ${ }^{3}$ during the initial testing of the TFTR Tritium Storage and Delivery System (TSDS). These tests indicated no significant charge leakage from the piezo crystal when using tritium at 2 atm and operating voltages as high as $+250 \mathrm{v}$. The tritium exposure ( $42 \mathrm{~atm}$-days) and the operating voltage $(250 \mathrm{v})$ represent substantial overtests for the currently anticipated scenario. The matter of impurity buildup was also investigated by the TSDS fabrication team, ${ }^{3,4}$ Ordinary hydrogen (protium) was the major exchange impurity observed after exposing the TFTR hudrogen piezo valve to pure tritium continuously for 15 hours, although 0.03 at.\% of carl, on (as methane) was also detected. Since unbaked, as-manufacturered, piezoelectric valves do not give, rise to unacceptable quantities of high-Z impurities, and since any reduction of organics in the valve for tritium compatibility should reduce these impurities further, this problem appears to recuire no special ättention. 
Despite the assurances above, the TFTR hydrogen valve has three serious shortcomings for the tritium injection program: (1) its tritium compatibility should be improved to ensure reliable performance throughout the anticipated schedule of tritium injections; (2) the maximum flow rate of the valve is too small by a factor of 10 . and past efforts to redesign the TFTR valve for increased throughput have met with only limited success; and (3) the valve requires complete disassembly and a delicate 3-screw adjustment to compensate for seat deterioration--an unacceptable feature for a valve that might require such adjustments after preliminary testing with tritium.

\section{THE TFTR TRITIUM INJECTION VALVE}

The solution to all three problems was to purchase and modify a piezoelectric valve of a new design from a different manufacturer.* This new valve (Fig. 1), as purchased from the manufacturer, has a flow rate adequate for the TFTR requirements, and it also features an external, single-screw adjustment to compensate for any changes in the valve seat material. The construction of the valve is such that ali static eiastomeric seals in the outer case can be easily replaced with metal seals.

The use of two relatively radiation-resistant organic materials for piczo valve seats was the subject of a recent paper. ${ }^{5}$ The authors analyzed (but did not actually test) two materials for which tritium effects on sealing properties had been independently established ${ }^{6}$--ethylene propylene rubber (EPDM), and high density polyethylene (HDPE). EPDM has elastic properties similar to Viton, a common fluoroelastomer that has already been used successfully in thousands cf these valves. EPDM is also usable at the TFTR bakeout temperature of $150^{\circ} \mathrm{C}$. HDPE has a compressional modulus approximately 100 times higher than that of normal elastomers and it has poor high-temperature properties. 5PDM elastomer therefore appeared to be the best choice for quick development of a low-risk piezolectric valve. The valve seat disk and other internal elastomers were thus replaced with EPDM, which is also expected to meet the TFTR requirements of low outgassing of high- $Z$ gases under tritium exposure.

Because compressiun set and loss of elasticity in the valve seat is certain to result from exposure to tritium, threshold holding voltage will also change, and there should exist a convenient means of adjusting the nozzle-seat geometry of the valve. As previously stated, the TFTR tritium-er npatible piezoelectric valve has an external single-screw adjustment for this purpose. This piston-type adjusting mechanism requires (wo) more EPIDM o-rings in the valve, which complicates the task of tritium hardening. Nevertheless the maximum adjustment allowed in the

- Model MV-112 Piezoelectric (jas I cak Valve, Max Tek Inc., 2908 Oregon Ci., Torrance, CA 9050.3 
TABLE II

MAXTEK MV-112 PIEZO VALVE

MATERIAL, SUBSTITUTIONS FOR COMPATIBILITY

\begin{tabular}{|c|c|c|c|}
\hline PART & $\begin{array}{l}\text { ORIGINAL } \\
\text { MATERIAL }\end{array}$ & $\begin{array}{c}\text { MAT'L } \\
\text { PROBLEM }\end{array}$ & $\begin{array}{l}\text { REPLACE } \\
\text { WITH }\end{array}$ \\
\hline FITTING O-RINGS & VITON & $\mathrm{T}$ & WELD IN \\
\hline ADJUSTER O-RINGS & VITON & $\mathrm{T}$ & EPDM \\
\hline WIRE INSULATION & TEFLON & TT & KAPTAN \\
\hline PRELOAD BAI L & TEFLON & TT & C.ERAMIC \\
\hline PRELOAD SPRING & $400 \mathrm{SS}$ & $M$ & $\mathrm{OK}$ \\
\hline SPACER O-RING & VITON & TT & EPDM \\
\hline MAIN BODY O-R.ING & VITON & $\mathrm{TT}$ & ALUMINUM \\
\hline CRYSTAL BONDING & EPOXY & $\mathrm{T}$ & OK \\
\hline CRYSTAL PLATING & NICKEL. & $\mathbf{M}$ & SIL VER \\
\hline VALVE SEAL DISK & VITON & TT & EPDM \\
\hline ADJUSTER SPRING & 400 ss & $\mathbf{M}$ & OK \\
\hline BNC CONNECTOR & TEFLON & TT & CERAMIC \\
\hline CONNECTOR O-RING & VITON & $\mathrm{T}$ & WELD IN \\
\hline
\end{tabular}

KEY TO MATERIAL PROBLEM:
$M$ - SL.IGHTLY MAGNETIC
$\Gamma$ - TRITIUM INCOMPATIBILITY.-MINOR
TT - TRITIUM INCOMPATIBILITY.-MAJOR

standard valve is only $0.15 \mathrm{~mm}$. and even a moderately hard o-ring should tolerate this. Table li idertifies all the components of the valve that are incumpatible either with tritium or with the high magnetic field, along with the material substitutions proposed.

The staff of TFTR tested an unmodified vilve and determined that it met their basic flow requirerients $(50 \mathrm{torr} \mathrm{L} / \mathrm{s}$ at 1500 ) torr inlet pressure and $150 \mathrm{vde}$ actuation)? Two specially modified valves were then purchased: one for tritium testing at los Alamos, and the other for furthe: hardering by elimination of all unnecessary elastomers. The only modifications made to these valves by the manufacturer were to replace all fluoroclastomer parts with EPIDM, and to substitute nonmagnetic silver for the stanciard nickel plating on the piezocelcc tric crystal. 


\section{TRITIUM EXPOSURE AND INJECTION TESTS}

At Los Alamos we conducted 9 series of 25 gas injections on one of the factory-modified valves, starting with 2 deuterium runs to establish basic valve performance, and gradually building up to 2 series of shots with pure tritium. Valve operating pulse parameters were kept constant (150 vdc for $450 \mathrm{~ms}$ ) throughout the eritire experimental program. Each 25-shot series was conducted in a single day, but the entire test program extended from March through Jine, 1987, with six weeks elapsing between the two pure-tritium runs. A final postexposure series was conducted with deuterium five months after the last tritium exposure and shot series. Table III summarizes the pertinent data from all these experiments.

TABLE III

PIEZO VALVE TRITIUM TESTS (DATA SUMMARY)

\begin{tabular}{lrllllr}
$\begin{array}{l}\text { Run } \\
\text { No. }\end{array}$ & DATE & $\begin{array}{l}\text { \% Q/Shot } \\
\text { Trit Torr-L }\end{array}$ & $\begin{array}{l}\text { Std } \\
\text { Dev }\end{array}$ & $\begin{array}{l}\text { Q(Tot) } \\
\text { Torr-L }\end{array}$ & $\begin{array}{l}\text { Torr } \\
-H r\end{array}$ \\
\hline 1 & $3 / 19 / 87$ & 0.00 & 24.43 & .15 & 109 & 0 \\
2 & $3 / 19 / 87$ & 0.00 & 25.03 & .41 & 375 & 0 \\
3 & $3 / 24 / 87$ & 0.10 & 28.61 & .14 & 713 & 7 \\
4 & $3 / 26 / 87$ & 1.02 & 29.27 & .06 & 731 & 31 \\
5 & $4 / 02 / 87$ & 2.43 & 30.47 & .07 & 761 & 73 \\
6 & $4 / 09 / 87$ & 9.86 & 31.09 & .30 & 766 & 250 \\
7 & $5 / 13 / 87$ & 98.66 & 24.58 & .09 & 613 & 2021 \\
8 & $6 / 29 / 87$ & 98.65 & 2273 & .21 & 524 & 1007 \\
9 & $11 / 23 / 87$ & 0.00 & 38.70 & .77 & 967 & 0 \\
\hline
\end{tabular}

A constant throughput per pulse was observed for each series of shots, for which the typical scatter is $0.2-0.5 \%$. The variation of mean throughput from one series to the next is significant and not altogether understoov. It may be related to the effects of compression se: of the EPDM valve seat material, but the conductance of the valve appears to increase between early runs in the serics, whereas it decreases between runs 6,7 , and 8 . This decrease may be associated with hardening of the elastomer, as these runs represent the most severe exposures to tritium. The throughput increased substan::ajiy for the final deuteruim ruil (No. 9) - more than caln be accounted for by the M. W. difference between tritium and deuteruim (see next piltagraph). The time modulation is linear and reproducible down to pulses of a few ms duration, so lower flow 
rates can be accurately obtained from the same valve. No significant deterioration in valve performance was detected during the Los Alamos tritium exposure and testing, and the available external adjustment was not needed in the course of these experiments.

In addition to the tabulated data, we report the following observations, which are important for the design of gas injector systems. In Run \#4 (10\% tritium, nominal) the tritiuni concentration actually varied from $\sim 20 \%$ in shot \#1 to $\sim 5 \%$ in shot \#25. This variation in concentration was an unavoidable result of our gas mixing method for all of our mixed isotope runs. We also observed a small but statistically significant increase in throughput per pulse as we progressed through this series. The conductance formula for viscous flow through an aperture contains a reciprocal square-root-of-molecular-weight term, ${ }^{8}$ and this effect is reflected in these data (increasing flow rate with decreasing mean molecular weight).

The second observation was that the closed test valve leaked a small quantity of gas across the seat whenever high pressure ( 1500 torr) was introduced suddenly to its inlet port. This characteristic is inherent in the design of this and most piezoeleciric valves. Although the crystal bimorph is pressure balanced in any static configuration, a transient differeniial pressure on the diaphragm can deflect it enough to allow a small quantity (20-25 torr-L) of gas to flow past the valve seat. This effect was only observed on initial pressurization of the previously evacuated valve, and no valve leakage was detected on subsequent repressurizations (from 1400 torr to 1500 torr).

The third observation relates to permeation of tritium through elastomers. Because the Los Alamos tritium exposure tests were conducted in a purgeable glovebox, there was no attempt to replace the elastomeric static seals in the outer valve body. When tritium concentration was increased to $100 \%$, the tritium concentration in the glovebox increased significantly, corresponding to a tritium leak rate of $10^{-6} \mathrm{~atm} \mathrm{~mL} / \mathrm{s}$. The leak appearec to come from the vicinity of the piezcelectric valve, but it could not be identified with any particular seal. We believe that this represents the cumulative permeation through all the elastomers in the unmodified valve body. This confirms the requirement that all elastomer seals in the outer body be replaced with weldments or all-metal compression seals, for which the permeation rates are insignificant at operating conditions.

\section{PROPOSAL FOR A COMPLETELY TRI AIUM-COMPATIBLE PIEZOELECTRIC VALVE}

A completely tritium-compatible piezoelectric valve was also proposed as a result of this study. This proposal (Fig. 2) is based on further modifications to the same rommercially available piezo valve that was tested for TFTR. It fentures fabrication from inorganic materials. including a sapphire valve seat and a metal-bellows-sealed cryscal preload adjustment. The company that manufactures the piezo valve described in this study has had limited success with a sapphire-seat piezo valve, but extensive developrent and es': ${ }^{9}$, would be required to ensure 
that such a valve met the performance, reliability, and seal integrity requirements relevant to tokamak tritium injections. This proposal was somewhat more ambitious than required for the TFTR experi-.ants, but is a desirable development for future fusion machines, for which the gas injectors will receive intense and chronic exposure from tritium, as well as from the much more intense rediations emanating from the DT-burning plasma.

\section{CONCLUSIONS}

A commercial pieznelectric gas injection valve was modified for enhanced tritium compatibility and tested with tritium for the anticipated program of tritium gas injections at TFTR. The valve tested provides the required maximum throughput of tritium gas ( 50 torr-L/sec) under operating parameters available from the TFTR computer contro! system and the TSDS tritium system. The valve's short-term repeatability is excellent when the injected pulse is controlled by time modulation at constant voltage. The time modulation is linear and reproducible down to pulses of a few ms duration, so the lower flow rates can be accurately obtained from the same valve. No significant deterioration in valve performance was detected in the course of the Los Alamos tritium exposure testing, which duplicated the schedule of exposures and injections the valve will see at TFTR. Static all-metal case seals, identical to those already qualified for tritium in TSTA applications, can be installed without changing the valve's functional design or affecting its operational performance.

\section{REFERENCES:}

${ }^{\prime}$ M. E. Thompson, H. F. Dylla, P. H. LaMarche, N. D. Arnold, W. A. Rauch, D. Mueller, and R. J. Hawryluk, "TFTR Gas Injection Control System Design and Operation," J. Vac. Sci. Technol. A (1985), 317-21, May/June 1986.

${ }^{2}$ H. F. Dylla and R. Hawryluk, Private Communication, Apr. 6, 1984.

${ }^{3}$ W. R. Wilkes, R. A. Watkins, and J. T. Gill, "TSDS, the Tritium Storage and Deiivery System for TFrR," Proc. Technol. Controlled Nuclear Fusion, 4th Amer. Nuc. Soc. Natl. Top. Mig., King of Prussia, PA, 1980, CONF-800427, 514-24.

4 J. T. Gill, B. E. Anderson, R. A. Watkins, and C. W. Pierce, "Tritium Storagc/Delivery and Associated Cleanup Systems for TFrR," J. Vac. Sci. Technol. A: 856-64, Apr./June 1983.

5 J. T. Gill and C. W. Pierce, "Predicted Effects of Tritium Exposure on Fast-Acting Piezoelectric Valves for Cas Fueling at TFTR," Fusion Technology 8: 2217-23, Sept. 1985.

6 P. E. Zapp, "Effects of Tritium in Elastomers," DP-MS-82-54, Savannah Rivar Laboratory, riken, SC, 1982. 
Fig. 2. Concept for a completely tritiumcompatible piezoelectric valve.

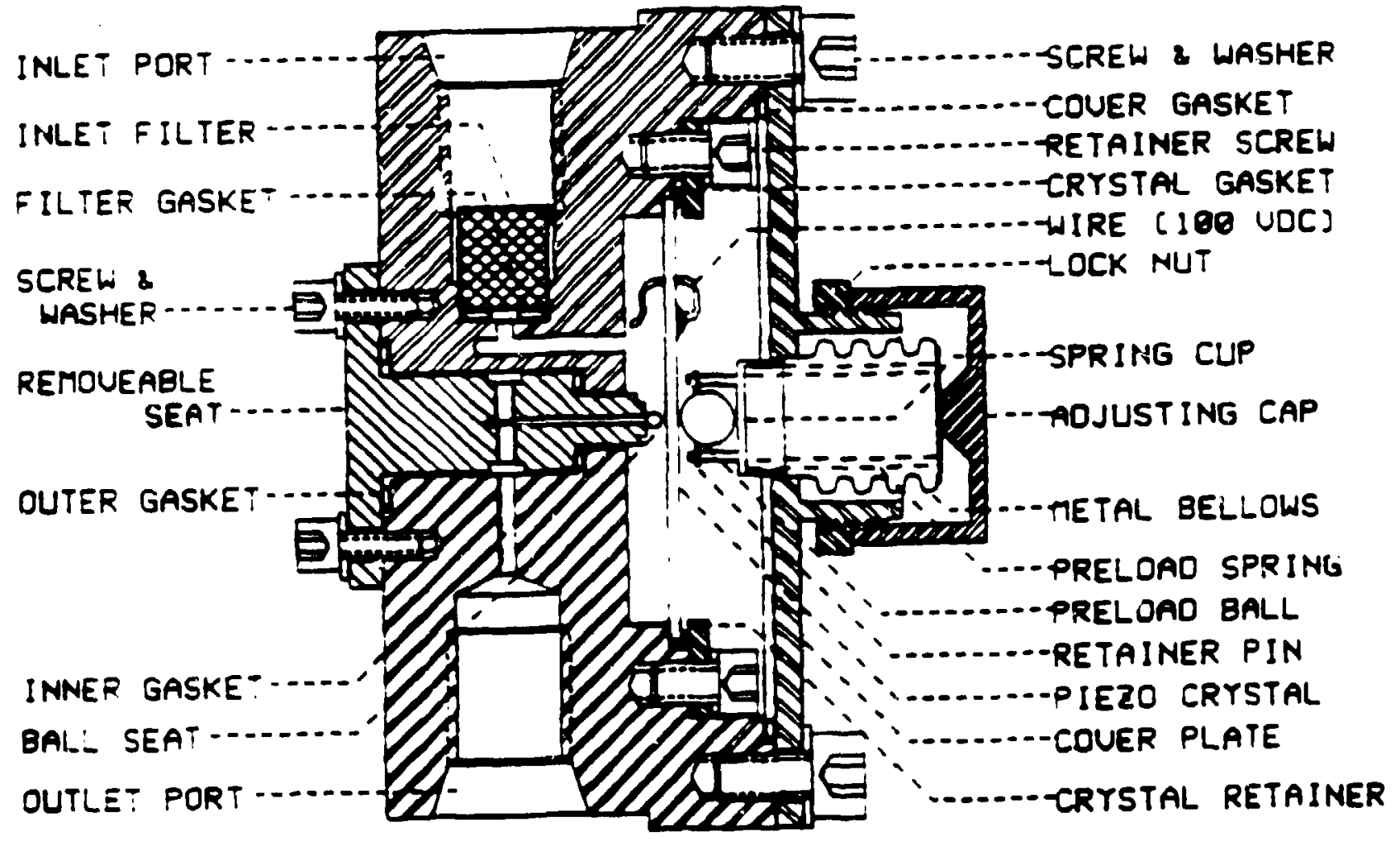


Fig. 2. Concept for a completely tritiumcompatible piezoelectric valve.

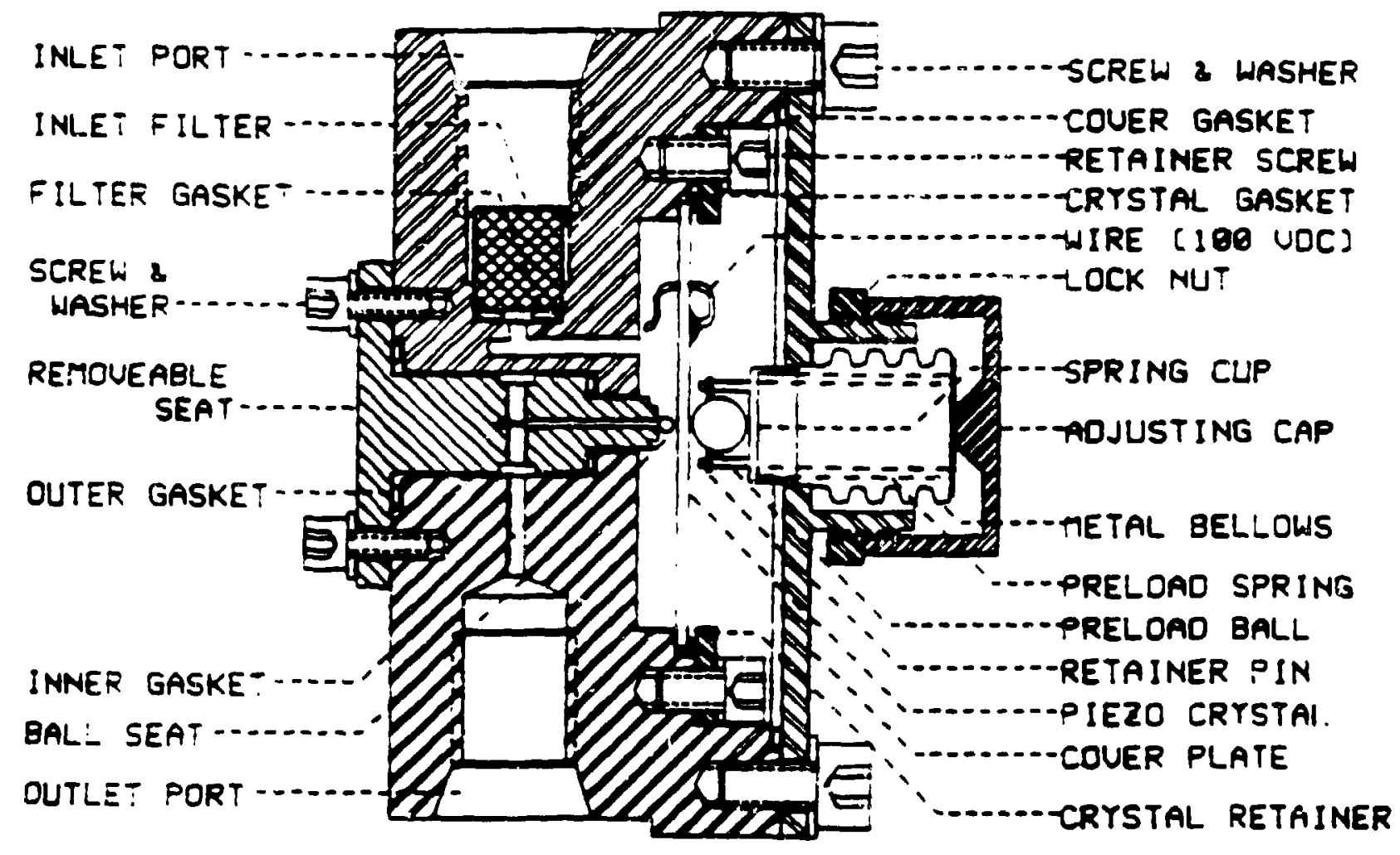


Fig. 1. The TFTR tritium-hardened piezoelectric valve.

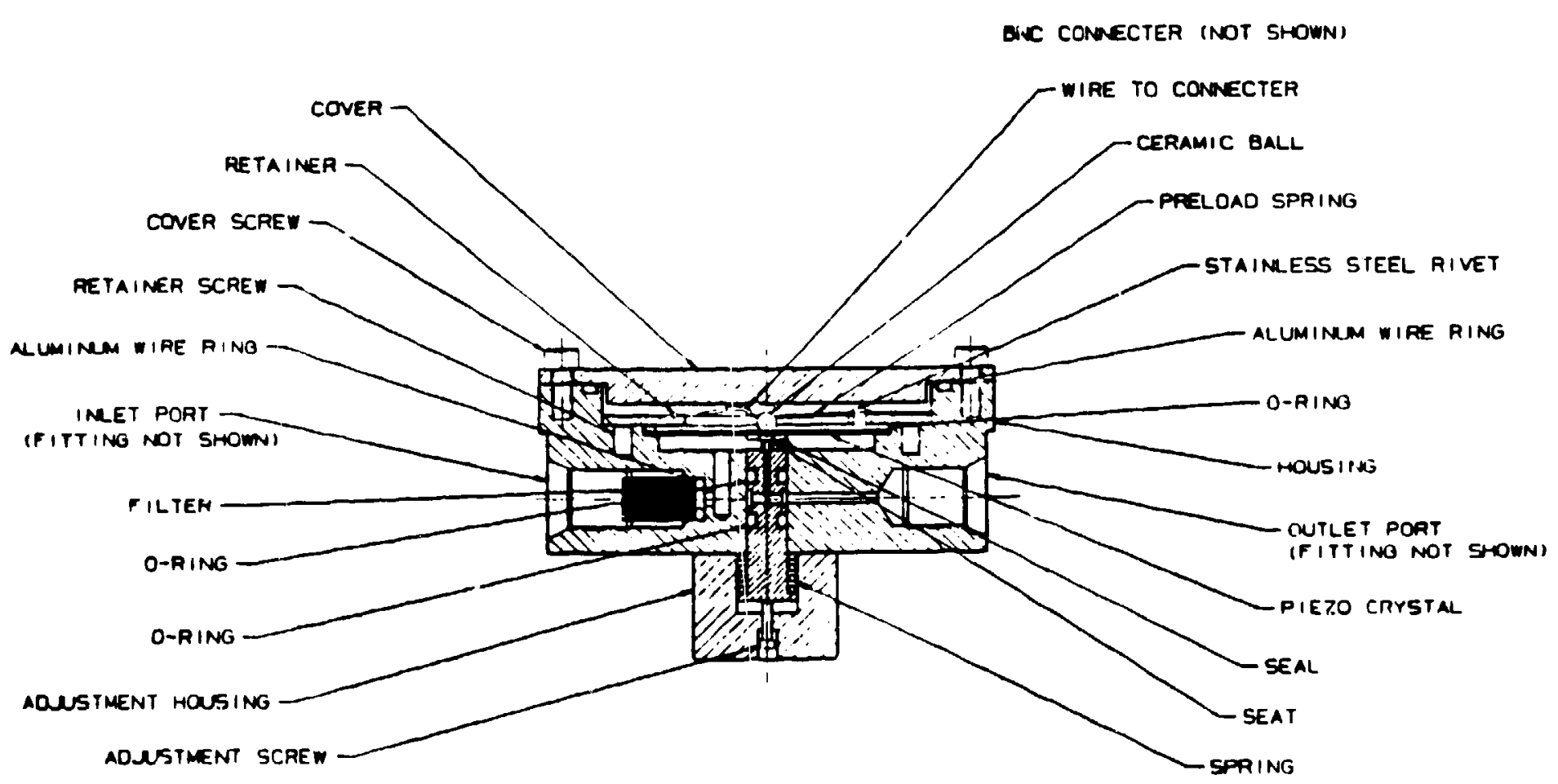


7 P. La Marche and W. Blanchard, Private Communication, 16 Oct. 1986.

8 A. Roth, "Vacuum Technology" (North-Holland Publishing Co., New York, 1976), p. 67.

9 Don Diem, MaxTek, Inc., 2908 Oregon Ct., Torrance, CA 90503. Private Cornmunication, 9 Apr. 1986. 